\title{
Commentary
}

\section{Ergonomics factors influencing school education during the COVID-19 pandemic: A literature review}

\author{
Mohammadreza Soltaninejad ${ }^{\mathrm{a}, \mathrm{b}}$, Amin Babaei-Pouya $^{\mathrm{c}}$, Mohsen Poursadeqiyan $^{\mathrm{d}, \mathrm{e}, *}$ \\ and Maryam Feiz Arefi ${ }^{\mathrm{d}, \mathrm{e}, *}$ \\ ${ }^{a}$ Department of Clinical Psychology and Department of Psychiatry, Roozbeh Hospital, Tehran University of \\ Medical Sciences, Tehran, Iran \\ ${ }^{\mathrm{b}}$ Rajaie Cardiovascular Medical and Research Center, Iran University of Medical Sciences, Tehran, Iran \\ ${ }^{\mathrm{c}}$ Department of Occupational Health Engineering, School of Health, Ardabil University of Medical Sciences, \\ Ardabil, Iran \\ ${ }^{\mathrm{d}}$ Department of Occupational Health Engineering, School of Health, Torbat Heydariyeh University of Medical \\ Sciences, Torbat Heydariyeh, Iran \\ ${ }^{\mathrm{e}}$ Health Sciences Research Center, Torbat Heydariyeh University of Medical Sciences, Torbat Heydariyeh, Iran
}

Received 15 September 2020

Accepted 2 November 2020

\begin{abstract}
.
BACKGROUND: The school is one of the most critical social, educational, and training institutions and the main pillar of education in society. Education and, consequently, educational environments have the highest effect on the mentality, development, growth, welfare, concentration, performance, and learning efficiency of students.

OBJECTIVE: The present study aimed to examine the effects of environmental ergonomics on the learning and cognition of pre-school students during the COVID-19 pandemic.

METHODS: The study was carried out as a review article using some keywords, namely "children", "learning", "preschool", "COVID-19", "ergonomics", and "environmental factors". Scopus, PubMed, Science Direct and Web of Science were searched to find related articles.

RESULTS: Factors like color, form, and layout of classrooms, lighting and ventilation, interior decoration, and educational equipment are effective in creating interest and motivation for students to learn.

CONCLUSIONS: A review of these articles showed that the presence of ergonomics in educational spaces for children increases the quality of learning and reduces stress and anxiety, and by observing health protocols, a healthy and safe environment can be provided for students.
\end{abstract}

Keywords: Ergonomics, school, COVID-19

\footnotetext{
*Address for correspondence: Dr. Mohsen Poursadeqiyan, Department of Occupational Health Engineering, School of Health, Torbat Heydariyeh University of Medical Sciences, Torbat Heydariyeh, Iran. Maryam Feiz Arefi, Health Sciences Research Center, Torbat Heydariyeh University of Medical Sciences, Torbat Heydariyeh, Iran. E-mails: mo.poursadeghiyan@uswr.ac.ir (Mohsen Poursadeqiyan) and f.arefi1390@gmail.com (Maryam Feiz Arefi).
}

\section{Introduction}

The school space is called the "third teacher" by famous experts, which consists of labs, hallways, building materials, wall colors, light, furniture, and all educational materials. School is a unique environment in which students live, learn, experience, and communicate with others $[1,2]$. In such an envi- 
ronment, education, personality growth, correct educational methods, a proper physical space, and also a favorable psychological space are formed and managed [3]. One of the factors influencing a child's personality is his/her environment, and schools are one of the environments in which children spend a great deal of their time. Researchers believe that personality growth is the result of the interaction between the individual and the environment. According to Washburn, the interaction of a child with the physical-social environment is a key factor in efficient learning and can only be achieved if there is a deep and experienced relationship in the environment [4]. The learning environment is formed by elements such as color, light, voice, equipment and schoolyard [5].

The specifications and quality of each one of these elements affect the formation of different behaviors. Jean Piaget puts great importance on the child's ability to comprehend the world actively. He believes that children do not receive information passively, but they see, hear, and feel the world around them, and then they choose and interpret $[5,6]$. One of the most fundamental concerns in revising the school environment is the observance of ergonomics in school. In other words, school is a large house in which many children and adolescents spend long hours of their lives. This place should be lovely so that students can enter it with enthusiasm and interest and learn science and knowledge with strong motivation and vitality. A beautiful, attractive, and hygienic school in which ergonomic standards are observed prepares the ground for better learning and the realization of talents. Such standards are about paying attention to students' health, improving educational environment quality, using standard equipment, and controlling posture disorders [7].

As part of a social-distancing policy in countries, schools in many countries are closed during the COVID-19 Pandemic [8]. Studies have shown that COVID-19 is highly contagious, and attending crowded and dense environments can increase the incidence of this disease [9]. Schools are among the highly dangerous places as they are densely populated with children. Also, children with this disease can transfer it to their family members and friends. Therefore, following the closure of schools, education has continued virtually. However, due to the continuation of the corona pandemic, the necessity of face-to-face education, and the need for students to attend schools, the school environment should be prepared based on the requirement of the pandemic period and under the health protocols recommended by health institutions. In such an environment, the safety of students and teachers is preserved while the education process is reestablished.

Based on ergonomics principles, schools are divided into four sections of students, educational environment, educational organization, and education. In each of these four sections, the environmental conditions of the educational facilities are crucial. Environmental variables such as school temperature, noise, lighting, dimensions of the classroom $[6,10]$, temperature, air quality, wall colors $[7,11]$, ventilation, bench layout, adequate space, and classroom layout are the factors affecting students' learning performance $[10,12]$. On the other hand, these variables should also be considered in the prevention of COVID-19. Therefore, with Considering the large population of students in Iran and the importance of maintaining the health of these national assets during the corona pandemic and considering the primary purpose of educational organizations, which is learning $[11,13]$, this study aims to review the ergonomic factors in schools during the COVID-19 pandemic.

\section{Method}

The study is a descriptive-analytical one to explain the necessity of ergonomics in the design of kindergarten and school spaces. The research was conducted by a literature review method. The research papers used in this study were found by searching ScienceDirect, PubMed, Scopus, and Web of Science databases. The search was done using keywords, namely "school", "learning", "COVID-19", "ergonomics", and "environmental factors".

\section{Results}

The term "learning environment" refers to a wide range of factors of micro design and macro economy that can affect learning $[14,15]$. Therefore, these factors are discussed separately in the following sections.

\subsection{Learning and cognition}

Education and the educational environment have the most effect on and role in the mentality and 
civilization of societies. Among the requirements of educational programming is to create environments related to students' activities. By such environments, suitable conditions for physical, mental, emotional, and social development are provided, and the realization of these environments entails paying attention to the details of spaces based on the behavioral patterns of children. By studying children's behaviors in educational environments, researchers have emphasized items like the area of schools, the layout of classrooms, lighting, the absence of noise, and ventilation, which play a prime role in enhancing learning performance $[5,6,16]$. Learning motivation is boosted in children when they experience an educational space, and they may have a sense of repulsion when this space is not consistent with their expectations, and as a result, children show no interest in learning. Factors like color, form, and layout of classrooms, lighting and ventilation, interior decoration, and educational equipment are effective in creating interest and motivation for students to learn [17].

A peaceful environment in schools depends on a mixture of several factors like adequate and suitable physical space, noise control, lighting, temperature, and hygiene $[12,18]$. However, due to specific limitations, educational environments tend to be soulless and uninteresting. Observing the standards and principles of designing educational environments can lead to the development of space appropriate to the psychological and spiritual needs of students and society as a whole $[17,19,20]$. Preschool facilities space has a key role in the development of students' potentials so that they affect the development of children's capacity to a specific level of growth and constructive interaction with the environment $[13,21]$. According to studies, the extent of peace and tranquility felt by individuals is affected by physical factors like light, noise, temperature, ventilation, and air quality $[17,22]$. Also, environmental factors like lighting, noise, temperature, and air quality affect learning [7, 11]. According to [23], light, temperature, air quality, and color affect educational development.

\subsection{Noise}

Noises beyond the standard level are critical obstacles to learning [18, 24]. Also, noise degrades the physical energy and performance of students [25]. Besides, noises outside the classroom may penetrate the classroom while students try to focus on the teacher's voices and only allow educational content into their brains. However, when the noise overshadows the teacher's voice, students stop focusing on what they hear, even the teacher's voice; this creates chaos in the classroom. Factors like classroom furniture, room shape, sound echo time, and noise source all affect students' hearing ability, and these factors should be taken into account in the design and construction of an educational environment [17]. The acoustics of a learning space has a relationship with noise control in this space. The main objective is to fulfill the quality requirements to generate and receive voices properly. The quality of auditory perception and noise control are two main aspects that determine the acoustics of a building. Easy auditory comprehension and being protected against background noise not only improve the connection with the lecturer but also improve learning performance [21, 26]. Holding classrooms in open spaces and the observance of social distancing can affect the quality of the teacher's voice heard by students and their ability to concentrate.

\subsection{Light}

Our knowledge of the world around us is mainly by seeing that it requires the presence of light [22]. The effect of light on the learning process is so high that $83 \%$ of it happens through light. Light has physical, spiritual, and physiological effects on the man so that it affects the activity, behavior, and performance of children in the classroom [22, 27]. Proper lighting improves visual perception and increases children's ability for the perception and cognition of visual information [24, 28]. Light can also help us have an exciting experience with space. However, the classroom should use natural light as much as possible. Classroom lighting is either through natural light (windows, openings, etc.) or artificial lights (by different types of lamps). The quality, direction, and quantity of light are highly important. As recommended by studies, the total area of windows should be at least one-fifth of that of the classroom to make sure that enough light for reading and writing enters the space. In addition to adequate light, the light distribution should be uniform in classroom space to avoid annoying reflexes and shadows. Lighting design should be based on a standard that protects eyes from bothering reflections or glares [29].

Students that enjoy more natural light in the classroom (e.g. daylight) have better performance than those using less natural light $[25,30]$. It is notable that sunlight also affects the temperature in the class- 
room, and it should be used given all its effects on the environment and requires balance [26, 31]. During the COVID-19 pandemic, some classes may be held in school gyms while the lighting of such spaces is designed for sports activities and is not suitable for educational purposes or reading and writing and thus decreases educational performance; it is because the distance between lights and bench surfaces in school gyms is too high.

\subsection{Temperature}

Over the past few decades, researchers have paid more attention to the optimum temperature for learning $[21,26]$. Results have shown that an increase in temperature and humidity makes students uncomfortable, and their performance decreases due to reduced attention. Therefore, a cooler environment is better for the learning performance of students [27, 32]. Also, the high temperature that causes sweating may cause distraction and decrease performance [10,12]. According to Haren, the best temperature range for learning, reading, and mathematics is $20-23.3^{\circ} \mathrm{C}$. Therefore, proper heating and cooling equipment should be used in the educational environment to avoid learning performance decline and other damages. The suitable temperature for the classroom is $18^{\circ} \mathrm{C}$. The best ways to adjust and control temperature are central heating/cooling systems; since using them is not possible in all schools, it is best to use long-tube gas heaters to provide adequate heating in the classrooms [17]. According to studies, the higher the temperature and humidity, the more discomfort felt by students, and as a result, they have lower performance and concentration [28, 33]. Studies have shown that low temperature facilitates the transmission of COVID 19 so that low temperature has a positive linear relationship with the expansion of the disease [34]. On the other hand, an increase in temperature has a significant effect on decreasing the number of patients [35]. Since schools are mostly open during fall and winter - i.e. the cold seasons - it is imperative to adjust the temperature of the educational environment properly and respect hygienic principles.

\subsection{Air quality}

Children are particularly vulnerable to a variety of contaminants due to their high respiratory rate and metabolic rate $[29,36]$. Exposure to low-quality air increases the rate of absence from the classroom and degrades teachers' ability to provide high-quality education [30, 37]. Therefore, it is essential to control contamination, unpleasant smell, air quality, and so on in the educational environment. Studies have shown that COVID-19 can be transmitted via air, coughing, sneezing, and talking within a few meters distance. The virus can be transmitted by airflow, and also it remains in the air for a few hours [38]. Therefore, students must use masks to prevent the spread of the virus in the classroom. If there are asymptomatic carriers in the classrooms and students do not wear masks, other students will be exposed to COVID-19. The number of students in the classrooms should be lowered to enable the students to keep a safe distance from others. Proper ventilation is also needed to decrease the concentration of contaminators. To this end, it is better to keep the windows and doors of classrooms open. A study at Harvard University on school students about the minimum air needed by students showed that with an increase in activity, individuals need more air than normal conditions. Also, classroom air should be refreshed three to five times every hour, and the concentration of $\mathrm{CO} 2$ must not exceed $1 \%$ [17].

\subsection{Educational space}

Studies have shown that the creativity and capabilities of an individual are formed during childhood and the best time to improve one's creativity and imagination power is between the ages of two and ten years [31,33]. The educational environment has a key and important role in learning [31, 40, 41]. An educational environment should be appropriate so that all children can activate freely in it. Also, benches should be suitable for students' use [32, 42]. Professor Gary Moore showed that the quality of newly designed spaces in preschool facilities, as a physical environment, affects the growth, cognitive development, and social behaviors of children [36, 43]. The size and form of spaces can facilitate the aggregation of individuals and the formation of social interactions $[37,45]$. Studies have shown that there is a direct relationship between the educational performance of students and classrooms' structural conditions. Therefore, it is imperative to take these variables into account to improve education standards in schools, preschools, and elementary schools $[46,47]$. Studies have shown that $72.5 \%$ of the surveyed schools did not have the required ergonomic conditions. The physical space of three-fourth of the surveyed schools lacks proper drinking water, toilets, and educational equipment (blackboard, bench, etc.) suitable 
for the psychological and physical conditions of students.

According to Moudi, the preschool age group are exposed to risks when they use such non-standard educational equipment. Another key issue is that many high schools or junior high schools are now used as elementary schools with previous equipment that does not fit elementary school children [46]. Factors such as classroom and building design also affect the success of the learning goal $[40,48]$. The dimensions of spaces, buildings, and any equipment and tool should be designed based on anthropometric measures done for the users. The first condition in designing any system from an ergonomic viewpoint is to pay attention to the size of the user of the system. Therefore, anthropometric measurements are among the widely used ergonomic data in the design process $[42,49]$. User characteristics and structural anthropometric dimensions must be taken into account in the design of any facility $[39,50]$. Students need appropriate furniture to sit or stand up without difficulty during the education-learning process [44]. Also, choosing the best suitable color is a top priority, and it is better to use light colors for children $[43,51]$.

Classrooms have the most important role in educational spaces as the main places where learning takes place. Classrooms can provide a variety of learning opportunities for different individuals. The layout of classroom furniture has a notable effect on the comfort felt by students and also their interaction with other students and teachers [52, 45]. Chairs should be comfortable, in line with ergonomic design principles, lightweight, durable, and easily moveable. Students cannot place their feet on the ground when their chair is too high, and this induces extra pressure on the hamstring muscles [47, 52] and blood circulation. Chairs with adjustable height can be a better choice than chairs with fixed height, as their height can be adjusted for different learning activities such as using laptops or desktop computers, and as a result, the distance between the user and screen is safe [48, 53].

The concerns about tables are similar to those of chairs in many cases. To maximize the flexibility of tables, they should be light and easy to move, and their height and size should be suitable for the learning activities of students. The height of the table should be proportional to the height of the chair. So that if chairs are adjustable, tables should be adjustable as well $[49,54]$. The use of tables and chairs with the required standard significantly improves the sit- ting posture and performance of students [3]. During the COVID-19 pandemic, gathering in closed spaces should be minimized, which means that the number of students in classrooms should be decreased. Therefore, schools can work in two different shifts to lower the number of children in classrooms. Also, the layout of classroom furniture should facilitate social distancing so that the distance between the positions of children should be at least $2 \mathrm{~m}$ [55].

It is notable that online and remote education is another option during the COVID-19 pandemic so that a group of students can stay at home and continue their education using mobile devices or desktop computers. These students also need to have a suitable chair and table at home based on their anthropometric variables. Studies have shown that neck aches, wrist pain, and shoulders and hands problems are prevalent in students who use mobile devices like phones and tablets [56]. Bending over or squatting in the long-run creates musculoskeletal problems in children [57]. Studies have reported trivial forms of accumulated disorders in students who use mobile phones [58, 59]. Besides, lighting should be enough at home to prevent damages to the eyes [60]. In short, the effects of environmental ergonomics, design of spaces, and lighting on performance in educational environments are emphasized [61]. Also, in the school environment, the type of carrying bags and backpacks and other management policies can affect the performance and efficiency of students [52-54].

\section{Conclusion}

School is an environment to realize the talents, creativity, and potentials of students. The physical condition at school has a direct effect on the comfort, concentration, performance, learning, and efficiency of students, and also the prevalence of diseases in them. Therefore, environmental factors such as light, noise, ventilation, temperature, inner space condition, and furniture layout should be taken into account in the design of schools. If these factors are not based on ergonomic standards, the connection between teachers and students might be interrupted and learning performance might be degraded. It is notable that negligence of environmental conditions and the effect of ergonomics on learning performance increases costs, and causes waste of assets, equipment, and energy, and decreases educational performance. A proper learning environment based on ergonomic standards not only creates motivation and facilitates 
the learning process, but also guarantees the organizational health of schools. It is notable that poor environmental condition creates obstacles to educational development, increases the transmission of diseases in students and personnel, and decreases educational performance. Also, observing hygienic protocols and combining hygienic and ergonomic principles surely have a positive effect on the educational performance of students.

\section{Conflict of interest}

\section{None to report.}

\section{References}

[1] Nikolić V, et al. Remodeling of the interior of preschool institutions in the context of improvement of ambient value and quality of space. Facta universitatis-series: Architecture and Civil Engineering. 2013;11(3):211-20.

[2] Močinić S, Feresin C. The role of the school space in preschoolers'learning processes. Humanities \& Social Sciences Reviews. 2017;5(2):98-108.

[3] Lafond D, et al. Postural development in school children: a cross-sectional study. Chiropractic \& Osteopathy. 2007;15(1): 1 .

[4] DeGregori, A., Learning enviroments: redefining the discourse on school architecture interactive [Accessed 17 January 2016]. Online access: http://archives.njit.edu/vol 01/etd/2000s/2007/njit-etd2007-034/njit-etd2007-034.pdf, 2007.

[5] Poursadeqiyan M, babaei a, Arefi MF. Health, safety, and environmental status of Iranian school: A systematic review. J Edu Health Promot. 2020.

[6] Adeyemi A, Yusuf S, Ezekiel O. Environmental Considerations toward the Provision of Conducive Learning Environments in Nigerian Schools. Arid Zone Journal of Engineering, Technology and Environment. 2017;13(4):449-57.

[7] Krüger EL, Zannin PH. Acoustic, thermal and luminous comfort in classrooms. Building and Environment. 2004;39(9):1055-63.

[8] Van Lancker W, Parolin Z. COVID-19, school closures, and child poverty: a social crisis in the making. The Lancet Public Health. 2020;5(5):e243-e244.

[9] Viner RM, et al. School closure and management practices during coronavirus outbreaks including COVID-19: a rapid systematic review. The Lancet Child \& Adolescent Health, 2020.

[10] Song G-S, Lim J-H, Ahn T.-K. Air conditioner operation behaviour based on students' skin temperature in a classroom. Applied Ergonomics. 2012;43(1):211-6.

[11] Lotfeatta A, The Impact of Environmental Factors on Learning and Behavior in (Primary) Educational Environments in the City. Urban Management. 2008;21(6):73-90. ]Persian[

[12] Berry MA. Healthy School Environment and Enhanced Educational Performance: The Case of Charles Young Elementary School, Washington, DC. 2002.
[13] Stanković D, Milojković A, Tanić M. Physical environment factors and their impact on the cognitive process and social behavior of children in the preschool facilities. Facta universitatis-series: Architecture and Civil Engineering. 2006;4(1):51-7.

[14] Legg S. Ergonomics in schools. Ergonomics. 2007;50:15239.

[15] Smith TJ. The ergonomics of learning: educational design and learning performance. Ergonomics. 2007;50:1530-46.

[16] Yang Z, Becerik-Gerber B, Mino L. A study on student perceptions of higher education classrooms: Impact of classroom attributes on student satisfaction and performance. Building and Environment. 2013;70:171-88.

[17] Houghton JT, et al. Climate change 2001: the scientific basis. Contribution of working group I to the third assessment report of the intergovernmental panel on climate change. 2001, Cambridge university press, Cambridge New York.

[18] Institute ANS. Acoustical performance criteria, design requirements, and guidelines for schools. 2002, Acoustical Society of America Melville, NY.

[19] Zandvliet DB, Straker LM. Physical and psychosocial aspects of the learning environment in information technology rich classrooms. Ergonomics. 2001;44(9):838-57.

[20] Hashim AM, Dawal SZM. Kano model and QFD integration approach for ergonomic design improvement. ProcediaSocial and Behavioral Sciences. 2012;57:22-32.

[21] Smith TJ. Integrating community ergonomics with educational ergonomics-designing community systems to support classroom learning. Work. 2012;41(Supplement 1):3676-84.

[22] Barrett $\mathrm{P}$, et al. The holistic impact of classroom spaces on learning in specific subjects. Environment and Behavior. 2017;49(4):425-51.

[23] Barkmann C, Wessolowski N, Schulte-Markwort M. Applicability and efficacy of variable light in schools. Physiology \& Behavior. 2012;105(3):621-7.

[24] Barrett P, Davies F, Zhang Y, Barrett L. The impact of classroom design on pupils' learning: Final results of a holistic, multi-level analysis. Building and Environment. 2015;89:118-33.

[25] Van Bommel W, Van den Beld G. Lighting for work: a review of visual and biological effects. Lighting Research \& Technology. 2004;36(4):255-66.

[26] Edwards C, Gandini L, Forman G. The hundred languages of children: The reggio emilia approach [to early childhood education]-advanced reflections. 1998: Ablex.

[27] Bellia L, Bisegna F, Spada G. Lighting in indoor environments: Visual and non-visual effects of light sources with different spectral power distributions. Building and Environment. 2011;46(10):1984-92.

[28] Wargocki P, Wyon DP. The effects of moderately raised classroom temperatures and classroom ventilation rate on the performance of schoolwork by children (RP-1257). Hvac \& R Research. 2007;13(2):193-220.

[29] King J, Marans R. The physical environment and learning process (Report No. 320-St2). Ann Arbor: University of Michigan Architectural Research Laboratory. School Board Journal. 1979;149(2):22-3.

[30] Crawford GN. Going Straight to the Source. American School \& University. 1998;70(6):26-8.

[31] Schneider M. Do School Facilities Affect Academic Outcomes? 2002.

[32] Smith T. The ergonomics of learning: educational design and learning performance. Ergonomics. 2007;50(10):153046. 
[33] Leccese Pinna M, Montessori M. Educazione alla libertá. 1986, Roma-Bari: Laterza.

[34] Bagheri and Azamati, Improving the Mental Health of Citizens by Designing an Urban Landscape. Human..[Persian] and Environment. 2009;7:88-95.

[35] Tobías A, Molina T. Is temperature reducing the transmission of COVID-19 ? Environmental Research. 2020;186:109553-109553.

[36] Xie J, Zhu Y. Association between ambient temperature and COVID-19 infection in 122 cities from China. Science of The Total Environment. 2020;724:138201.

[37] Moore GT. The physical environment and cognitive development in child-care centers, in Spaces for children. 1987, Springer. pp. 41-72.

[38] Hornecker E. Space and Place-setting the stage for social interaction. in Position paper presented at ECSCW05 workshop Settings for Collaboration: The Role of Place. 2005.

[39] Morawska L, Milton DK. It is time to address airborne transmission of COVID-19. Clin Infect Dis. 2020;6:ciaa939.

[40] Das B, Kozey JW. Structural anthropometric measurements for wheelchair mobile adults. Applied Ergonomics. 1999;30(5):385-90.

[41] Woodcock A, Woolner A, Benedyk R. Applying the Hexagon-Spindle Model to the design of school environments for children with Autistic spectrum disorders. Work. 2009;32(3):249-59.

[42] Žunjić A, Papić G, Bojović B, Matija L, Slavković G, Lukić $\mathrm{P}$. The role of ergonomics in the improvement of quality of education. FME Transactions. 2015;43(1):82-7.

[43] Barl, Ö, et al. Anthropometric Evaluation of the Kindergarten Children Furniture in Turkey. Atatürk Üniversitesi Sosyal Bilimler Enstitüsü Dergisi. 2005;6(2):385-404.

[44] Frieling H. Farbe hilft verkaufen: Farbenlehre und Farbenpsychologie für Handel und Werbung. 1980: MusterSchmidt.

[45] Burgess B, Kaya N. Gender Differences in Student Attitude for Seating Layout in College Classrooms. College Student Journal. 2007;41(4).

[46] Alexander D, Lewis L. Condition of America's Public School Facilities: 2012-13. First Look. NCES 2014-022. National Center for Education Statistics, 2014.

[47] Kane P, Pilcher M, Legg S. Development of a furniture system to match student needs in New Zealand schools. in 16th World Congress on Ergonomics. 2006.

[48] Wadsworth A. Furniture and Equipment in Schools: A Purchasing Guide. Managing School Facilities, Guide 7. 2000: ERIC.

[49] Breithecker D. The educational workplace: What the "classroom of the future" will look like. Wiesbaden: Bundesarbeitsgemeinschaft für Haltungs und Bewegungsförderung, 2005.
[50] Arefi MF, Poursadeqiyan M. Investigating the match between anthropometric measures and the classroom furniture dimensions in Iranian students with health approach. A systematic review. J Edu Health Promot 2020;55:56.

[51] [Persian] Zofen sh, Lotfi Pour Kh, (1998); (Production and Use of Educational Materials) Educational Theachers.

[52] Poursadeghiyan M, Azrah K, Biglari H, Ebrahimi MH, Yarmohammadi H, Baneshi MM, et al. Effects of The Manner of Carrying The Bags on Musculoskeletal Symptoms in School Students in The City of Ilam, Iran, Ann Trop med Public Health. 2017;10(3):600-5.

[53] Hassankiadeh R, Faghihnia Torshizi Y. The new structure of economic evaluation health, safety and environmentmanagement system (HSE-MS) approach to estimate the cost of accident human. Iran Occupational Health. 2019;15(6):48-59.

[54] Mehrabi Matin A, Nazari Z, Ebrahimi MH, Poursadeghiyan M, Yarmohammadi $H$, Raei Mehdi. Measurement of chair dimensions used by nurses and comparing with ANSI/HFES100 standard. IJPT. 2016;8(2):14028-37.

[55] Melnick H, Darling-Hammond L. Reopening Schools in the Context of COVID-19: Health and Safety Guidelines from Other Countries. Policy Brief. Learning Policy Institute, 2020.

[56] Toh SH, et al. Mobile touch screen device use and associations with musculoskeletal symptoms and visual health in a nationally representative sample of Singaporean adolescents. Ergonomics. 2019;62(6):778-93.

[57] Gustafsson E. Ergonomic recommendations when texting on mobile phones. Work. 2012;41(Supplement 1):57055706.

[58] Eapen C, Kumar B, Bhat AK. Prevalence of cumulative trauma disorders in cell phone users. Journal of Musculoskeletal Research. 2010;13(03):137-45.

[59] Straker L, et al. Mobile technology dominates school children's IT use in an advantaged school community and is associated with musculoskeletal and visual symptoms. Ergonomics. 2018;61(5):658-69.

[60] Karchani M, Mazloumi A, NaslSaraji G, Akbarzadeh A, Niknezhad A, Ebrahimi MH, Raei M, Khandan M. Association of subjective and interpretive drowsiness with facial dynamic changes in simulator driving. J Res Health Sci. 2015;15(4):250-5.

[61] Vatani J, Nasl SG, Pourreza A, Salesi M, Mohammad FI, Zakerian SA. The relative costs of accidents following the establishment of the health, safety and environment management system (HSE-MS) for the construction industry in Tehran. 